American Journal of Economics and Business Administration 4 (1): 65-71, 2012

ISSN 1945-5488

(C) 2012 Science Publications

\title{
A Practical Framework for the Continuous Advancement of Entrepreneurship Education
}

\author{
${ }^{1}$ Robin Anderson, ${ }^{2}$ Brooke R. Envick and ${ }^{3}$ Prasad Padmanabhan \\ ${ }^{1}$ Pamplin School of Business, University of Portland, Portland, Oregon, USA \\ ${ }^{2}$ Meadows Center, St. Mary's University, San Antonio, Texas, USA \\ ${ }^{3}$ Departments of Finance, \\ Myra Stafford Pryor Chair of Free Enterprise and Sam Walton Fellow, \\ Alkek 236, Bill Greehey School of Business, St. Mary's University, \\ One Camino Santa Maria, San Antonio, Texas 78228, USA
}

\begin{abstract}
Problem statement: As the business environment becomes more and more complex due to rapid globalization, increasing competition and advancing technologies, universities are under more pressure to respond by providing students with experiential learning opportunities that mirror reality. In this study, we attempt to provide a better learning experience for students. Specifically, we provide a framework from a student learning perspective that improves our capability to determine what the goals and objectives should be for entrepreneurship education and how they could be modified or adjusted to maximize student learning experiences. Conclusion/Recommendations: We identify three distinct types of "zones" -the comfort zone, the learning zone and the panic zone to help identify appropriate activities to include in specific courses. It is a framework other universities can easily use to better understand and improve upon a specific entrepreneurship course and program offerings to help maximize student learning. Although this paper targets students in an entrepreneurship program, it is sufficiently general for utilization in other areas as well.
\end{abstract}

Key words: Framework, entrepreneurship, education, environment, zones, learning zone

\section{INTRODUCTION}

During the last decade, the world has witnessed unprecedented global competition for jobs. This competition has forced students to be able to demonstrate an ability to successfully handle increasingly complex problems in an integrated world to be able to secure employment. At the same time, the supply of colleges and universities seeking students has increased dramatically. To adequately differentiate themselves, academic institutions have been forced to adapt their curricular offerings to address the dual requirements of training students for rewarding careers as well as preparing them for life outside of their careers. Colleges and universities are therefore challenged to provide an adequate education to students that enhance their marketability in an integrated world, but also provide them with tools to solve problems that surface in their personal lives as well.

The framework presented in this study is an attempt to respond to these challenges in a practical way that allows universities to continually advance entrepreneurship education to meet the rising demands of the ever changing business environment (at the outset, we would like to state that the model presented in not in the spirit of traditional academic models-where a conceptual theoretical model is presented or tested and the results either validate or invalidate the proposed model. Here, we present a practical model that can be adapted by academics in any manner they choose to better educate students in any discipline) a brief literature review is presented, followed by a description of the learning zone framework. Examples of the application of the learning zone framework are provided for support, followed by suggestions and conclusions.

Literature review: Since 2000, entrepreneurial programs and courses in the college and business school curricula have increased considerably (Osborne et al., 2000). More and more, there is recognition that small businesses create the majority of new jobs in the country (Nunn and Ehlen, 2001) and increased competition for students has forced colleges and universities to attempt to differentiate their course

Corresponding Author: Prasad Padmanabhan, Departments of Finance, Myra Stafford Pryor Chair of Free Enterprise and Sam Walton Fellow, Alkek 236, Bill Greehey School of Business, St. Mary's University,

One Camino Santa Maria, San Antonio, Texas 78228, USA Tel: 210-431-2034 
offerings from each other to attract students. As a consequence, colleges and universities offering entrepreneurship courses have been forced to critically examine the specific content of entrepreneurship courses, as well as the associated learning and assessment objectives related to these courses.

In essence, colleges and universities are faced with the dual challenge of providing a transformative experience for students while providing professional programs that are relevant to students and their career choices. In the course of fulfilling these objectives, there is a critical need to ensure that students are challenged adequately in a college/university setting to maximize their learning experiences. Until recently, however, undergraduate education remained compartmentalized into rigidly defined disciplines and with the perception that entrepreneurship students lacked the requisite tools to adequately function in the real world, characterized by increasing uncertainty and global change (Smith et al., 2000). Similarly, Bennis and Thomas (2002) suggest, through their 'crucible of learning' article, that colleges need to teach students how to embrace uncertainty and global change. They argue that great leaders require the same skill sets as those required to conquer adversity. Clearly, colleges that can teach these skills when students are still in college will also be developing great leaders (we thank an anonymous reviewer for bringing this article to our attention).

Since entrepreneurship, by definition, is an area of study that is centered in dealing with ambiguity, uncertainty and complexity, it remains the responsibility of colleges and universities to adequately train students to deal with the real world. Although entrepreneurs are able to tolerate uncertainty and ambiguity better than others (Emmett, 1999; Glennon et al., 1966; Begley and Boyd, 1987; Lambing and Kuehl, 2000; Endo and Harpel, 1982; Envick and Padmanabhan, 2006; Kahn, 2002; Kuh, 1994; 1995; Pascarella, 1980; Pascarella and Terenzini, 1991; Wallace, 1967), to the best of our knowledge, there is no evidence that we are able to adequately measure whether the training they receive in colleges and universities add value in the real world.

Finally, to add another variable, the increasingly globalized world has forced colleges and universities to offer courses that teach these skills bearing in mind the true nature of competition. As a consequence, a typical entrepreneurship program offers an introductory course in entrepreneurship, followed by practical courses such as business plan development and small business growth and a culminating global entrepreneurship course of varying degrees of complexity and intensity. In particular, global entrepreneurship courses have become increasingly common as universities try to further develop the entrepreneurship curriculum offerings. In these courses, students may even have the opportunity to travel and test out their ideas in a foreign environment.

Given the importance of international entrepreneurship education, it becomes a critical area for maximizing student learning experiences. In this study, we utilized international entrepreneurship to illustrate the learning zone, as well as the inadequacies of comfort and panic zones.

The learning zone: A comfort zone is defined as an environment in which students feel at ease, secure and content. They are subject to almost no risk and are not pushed beyond any areas in which they are very familiar and comfortable. Examples include listening to lectures, taking exams, working on case studies, presenting their work to the professor and other students in the class and working on team projects. All of these activities are useful and provide students the opportunity to learn, but they do not mirror the reality of the ever changing and highly competitive business environment that consists of rapid globalization, advancing technologies and increasing competition. Keeping students in the comfort zone are appropriate for introductory courses and some intermediate courses. However, the authors argue that other opportunities for students need to exist in some intermediate courses and in all advanced courses that maximize student learning. Taking students out of their comfort zones and putting them into the learning zone is necessary to achieve this.

The learning zone is defined as an environment in which students feel eustress, which is the type of stress that is healthy and gives one a feeling of fulfillment. It is a controlled stress that provides us with a competitive edge in performance related activities such as job interviews, public speeches, or business plan competitions. The learning zone is the theoretical backbone of the framework presented in this study.

The authors contend that for some intermediate courses and for all advanced courses in entrepreneurship, it is essential to pull students out of their comfort zones, either deliberately or inadvertently and offer opportunities for experiential learning to occur at the highest level possible. A good example is to have students conduct interviews with local entrepreneurs or set up business meetings to present their own ideas. Another example is to provide students the opportunity to participate in a business plan or elevator pitch competition. International business trips are also ideal for international entrepreneurship courses.

The panic zone is defined as an environment in which students feel distress, which is the type of stress 
that is unhealthy and results in a state of adversity and psychological suffering. Students may be forced, either deliberately or by chance, in a zone where panic sets in. Clearly, there may be some on-the-spot learning that takes place in this zone, but the overriding emotion faced by the student is one of panic and little learning takes place in this zone. It is important to be cognizant of this state and avoid pushing students into the panic zone, as the distress may cause real risks to the student and overall success of the specific course or program (The zones of learning can also be referred to as a continuum of learning. Student presence in the panic zone can take away opportunities for learning. Hence, students should be directed away from distress panic zones since it reduces opportunities to acquire knowledge. We thank an anonymous reviewer for this link).

The learning zone model is presented in Fig. 1. To fully maximize learning, the student should be in the learning zone and not in the comfort or panic zone. To ensure the situation is managed properly, the professor should be in their comfort zone and not in the learning zone with the student and certainly not in the panic zone. Taking that into consideration, relative scores of the three zones for both the professor and students are presented in Table 1 from most favorable $=3$ to least favorable $=1$. Combinations of all scenarios are provided in Table 2 from the best-case of the worst-case scenario. The best- case scenario assumes that student learning occurs at the highest level and the worst-case scenario assumes almost no learning occurs at all.

Examples of application: The application of these the zones is illustrated in this section using a well established entrepreneurship program at a liberal arts university. The program contains a carefully selecting a blend of traditional classroom learning with opportunities outside of the classroom to enhance entrepreneurial education and experiences.

\begin{tabular}{llll}
\multicolumn{4}{l}{ Table 1: Zone rankings for student and professors } \\
\hline Rank & Student & Professor & Score \\
\hline 1$)$ & Learning Zone & Comfort Zone & 3 \\
$2)$ & Comfort Zone & Learning Zone & 2 \\
$3)$ & Panic Zone & Panic Zone & 1 \\
\hline
\end{tabular}

Table 2: Best to worst-case zone scenarios

\begin{tabular}{lllllll}
\hline Rank & Student & Score & & Professor & Score & Index \\
\hline 1) & Learning Zone & 3 & x & Comfort Zone & 3 & 9 \\
2) & Comfort Zone & 2 & x & Comfort Zone & 3 & 6 \\
2) & Learning Zone & 3 & x & Learning Zone & 2 & 6 \\
4) & Comfort Zone & 2 & x & Learning Zone & 2 & 4 \\
$4)$ & Learning Zone & 3 & x & Panic Zone & 1 & 4 \\
5) & Panic Zone & 1 & x & Comfort Zone & 3 & 3 \\
6) & Comfort Zone & 2 & x & Panic Zone & 1 & 2 \\
$6)$ & Panic Zone & 1 & x & Learning Zone & 2 & 2 \\
$7)$ & Panic Zone & 1 & x & Panic Zone & 1 & 1 \\
\hline
\end{tabular}

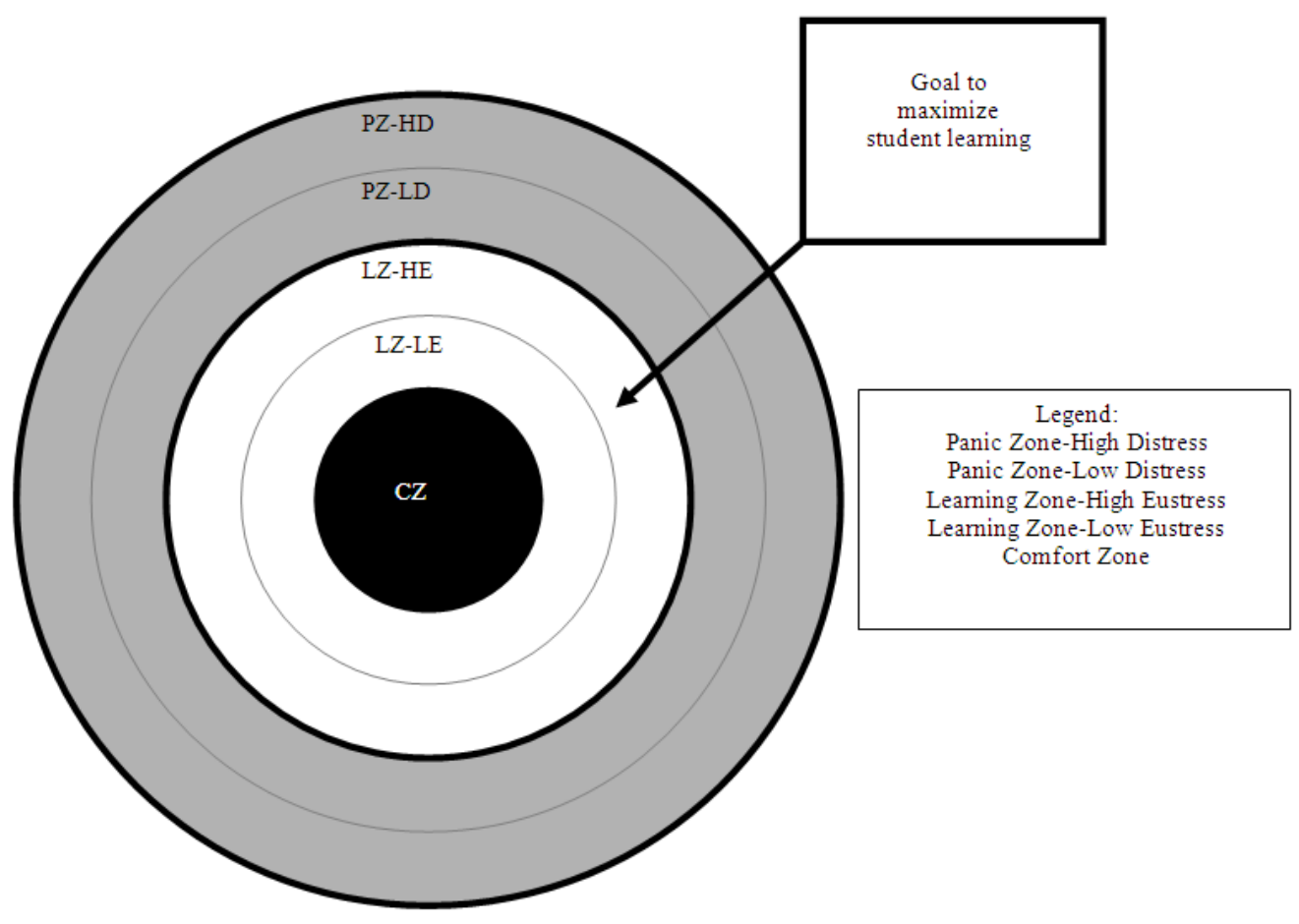

Fig. 1: Learning zone model 
The program overcomes five common barriers to learning: isolation, time, limited expertise, rapid globalization and cost. A traditional classroom setting isolates students from other useful learning environments such as local business seminars and workshops or national conferences. This program encourages and funds students to attend as many local business events as they can as well as a national conference. Additionally, the program affords the students the opportunity to take an international business trip, which is a part of the global entrepreneurship course. Students in the program have traveled to China and Russia and Taiwan. The purpose of the international business trip is to develop local business contacts, put students squarely in the learning zone and allow them to test their business idea in the international environment.

As the premise of this study conveys, the primary purpose of an advanced global entrepreneurship course is to get students out of their comfort zones and into their learning zones. Three examples are provided for illustrative purposes, with the first trip being much more successful than the second trip, from a learning perspective. The third trip to Taiwan was the most successful due to a variety of activities that spans the spectrum of comfort and learning zones for both the professor and students.

For all trips, students looked at their business concepts and addressed questions such as whether consumers from that country would purchase their products/services, how they would protect intellectual property and what modifications would have to be made to the product/service to make it work. Prior to traveling to these countries, students spent time working on a business plan (or the feasibility study) as it would apply to the foreign country. Student level preparations included reading about the economy and the culture of the country and how business relationships are established. They also had to develop a list of questions related to these focal points and at the same time assimilate knowledge about the entrepreneurial culture. Since students had to develop their own business plans and feasibility studies, they were behaving as real entrepreneurs and asking the type of questions that they would ask in a real world setting.

The following examples provide a good depiction of a good scenario, a scenario that was far less successful and a best-case scenario. The learning experiences gained all hinge on whether both students and professors occupied the appropriate zones.

China example: For the trip to China, the professor was in the comfort zone, having conducted previous business trips to that country and being very familiar with the culture and economy. The professor even had business contacts in the country and connected with another university during that trip that operates a similar program. The accompanying professor was also very familiar with the culture and economy of China, had been in the country numerous times with established contacts in more than one city. Additionally, the knowledge base regarding travel issues to and from China was well developed (i.e., pretravel preparations, lodging and transportation). The students were all in the learning zone. While a few may have moved in and out of the panic zone from time to time, they never felt a constant state of "distress" resulting in adversity and psychological suffering. The professors were clearly in their comfort zones and could easily identify when certain students slipped into the panic zone and responded by pulling them back into the learning zone. However, students were not generally placed in a position of eustress, since they were not called upon to speak in front of local audiences (for example, business persons).

Referring back to Table 2, the zone combinations of the students and professors (score of 9/9) for the China business trip provided an international experience that is considered a "good scenario". A significant amount of learning occurred on the part of the students, while the professors were able to alter the structure of the environment and the requirements of the students throughout the trip because they were in the comfort zone, which was established by a solid knowledge base. On the way back from China, the students told that professor that the trip to Beijing was worth $100 \mathrm{~h}$ in the classroom.

Russia example: For the trip to Russia, neither the professor nor the students had any experience in the country. More time had to be spent by the professor and students learning about the culture and economy through reading materials. Business contacts had to be established via e-mail and phone and through third parties. The knowledge-base regarding travel issues such as pre-travel arrangements, lodging and transportation was far less developed than in the case of China. All of this created a sense of angst even before the trip actually occurred. In fact, one student was visible in the panic zone and almost did not go on the trip. This student had not adequately prepared for his first international trip and did not a confirmed set of interviews with firms in Russia. To compound this problem, he did not pursue the leads offered by the professor in charge, whereas the other students had done so (this experience clearly placed this student in 
perpetual panic mode). The other students hovered between the panic zone and learning zone, but were never comfortable enough to establish them squarely in the learning zone. These students were operating in an environment which placed them in an alien culture and language. Furthermore, they did not have sufficient control over process, since a local agency was responsible for all logistics (it is interesting to note that while the other students were in a panic mode some of the time, they were experiencing this mode as a group. This allowed them to eventually recover from this mode and learn a lot (they were in eustress mode most of the time). They quickly realized that their own business plans developed in the US would not work in Russia and their eustress state forced them to come up with new plans while in Russia. While travelling around Moscow, they were able to see what kind of products would work in Russia and develop business plans. These plans were very well received locally). The professor was also operating from the learning zone. Substantial international business and travel experience prevented any sort of panic on his part, but the lack of knowledge simply did not allow the processor to operate from the comfort zone.

Referring back to Table 2, the zone combinations of the students and professor (initial score of 2/9) for the Russia trip provided an international experience that clearly did not maximize student learning. While the comfort level of the students did improve throughout the trip to the learning zone for some students (score of 6/9), it still did not live up to the trip to China in terms of student learning experiences. Also, the time period it took to get from a score of 2 to a score of 6 is costly, because there is only a limited amount of time and learning opportunities for each trip. Any time spent in the panic zone is wasted time, thus resulting in other wasted resources, which ultimately diminishes the purpose of the international business trip. follows:

Some interesting insights from this trip are as

- If students experience the panic zone as a group, their empathy for each other allows them to get out of this zone very quickly. Clearly, based on this extreme experience, if students are placed in the panic zone, they should be placed in this zone as a group. We conjecture that the sharing of collective plights allows for quicker recovery.

- According to (Bennis and Thomas, 2002) students can learn from conquering anxiety and stress and emerge stronger following this experience. Future leaders can emerge from such extreme experiences. Perhaps students' in future global entrepreneurship classes should be deliberately allowed to experience the panic zone.

Taiwan example: The E-Scholars' students travel to Taipei, Taiwan represents the "best case scenario", since students were forced to get out of their comfort zones and speak before a business audience. Moreover, the professor has been rarely out of his comfort zone; In addition, students were involved in many other activities that represented different degrees of learning on their part. Since this is the trip that captures all of the various zones of learning for the professor and the students, it is presented in more detail.

Basically, during the weeklong trip to Taipei, students:

- Made elevator pitches of their business plans to an audience made up of Taiwanese businesspersons (2 CEOs and 2 Vice Presidents of Venture Capital companies)

- Visited and interacted with faculty and students of a local university in Taipei

- Participated in company visits to several local companies where company personnel made presentations to the group. These were followed by fruitful interactions between company personnel and the students

- Met with St. Mary's alumni in Taipei

- Participated in the luncheon meeting of the local chapter of the Rotary Club

- Met international business persons at a local Trade Fair. They also met with many international business persons staying at the hotel. They used these opportunities to further enrich their business plans

- Visited many local cultural sites. These visits conveyed a sense of the local cultural heritage to students

- Found some time to visit Taipei on their own. They took this opportunity to visit some the 'back roads' of Taiwan, where they were able to absorb some of the local culture on display

These trips are presented in a zonal framework in Table 3. Clearly, given the range of activities on this trip, students were able to derive substantial learning related benefits from the trip. For the elevator pitches delivered to local business persons, students were able to defend their business plans in a foreign country and under the scrutiny of local business persons. The professor observed some elements of panic by some students during their presentations, but was able to pull them back by offering some accommodating suggestions. 
Am. J. of Economics and Business Administration 4 (1): 65-71, 2012

Table 3: Identification of zones for various activities, Taiwan trip

\begin{tabular}{|c|c|c|c|c|c|}
\hline Activity & Student & Score & Professor & Score & Index \\
\hline Elevator Pitch & $\begin{array}{l}\text { Learning Zone } \\
\text { (With eustress) }\end{array}$ & 3.0 & Comfort Zone & 3 & 9.0 \\
\hline Interactions with local university & Comfort Zone & 2.0 & Comfort Zone & 3 & 6.0 \\
\hline Company Visits & $\begin{array}{l}\text { Learning Zone } \\
\text { (Without eustress) }\end{array}$ & 2.5 & Comfort Zone & 3 & 7.5 \\
\hline Visits with alumni & Comfort Zone & 2.0 & Comfort Zone & 3 & 6.0 \\
\hline Rotary Club Luncheon & Comfort Zone & 2.0 & Comfort Zone & 3 & 6.0 \\
\hline \multirow[t]{2}{*}{ Trade Fair/hotel meetings } & Comfort Zone/Learning & & & & \\
\hline & Zone (with some eustress) & 2.5 & Comfort Zone & 3 & 7.5 \\
\hline Cultural visits & Comfort Zone & 2.0 & Comfort Zone & 3 & 6.0 \\
\hline Independent student cultural trips & Comfort Zone & 1.5 & Comfort Zone & 3 & 4.5 \\
\hline
\end{tabular}

Clearly, students were able to extract substantial earning from this activity. Similarly, other activities conducted in Taiwan had different index scores based on the learning zone model and are presented in Table 3.

\section{CONCLUSION}

The examples provided in this study refer to an international entrepreneurship course. However, the framework proposed is applicable to almost any entrepreneurship course or program. For example, if a group of students were to enter a regional business plan competition, the same combination of zones between professors and students apply. You would clearly want the professor to be in the comfort zone (i.e., understand business plans, know the rules of the competition, have experience prepping students for the competition), while the students would perform best in the learning zone, where they are experiencing eustress, which provides them a competitive edge.

Some steps may be necessary to either move professors into the comfort zone and students in the learning zone for specific projects, courses, or even programs. Obviously, the professor has control over the structure of the course and that provides the capability to increase or decrease the level of the comfort zone faced by students. For example, in the case of international travel, the professor can provide a list of ready contacts developed during earlier visits to the country. Alternatively, the professor can suggest a list of general contacts, such as the American Chamber of Commerce in the foreign location and make the students go through the process of making contact. In yet another variation, the professor can allow students to attempt to establish contact, but have an unannounced contingency list of contacts that students can use if their contact attempts fail.

In addition, the comfort zones of students are also influenced by their respective backgrounds. For instance, students with extensive international travel may remain in the comfort zone on an international trip. Obviously, some professors must take care to fine tune the learning environment for students with diverse backgrounds to maximize the learning zones for all students. As such, the assignments can be tailored differently for different students. If there are enough students to form groups, the group membership can be tailored in such a way to make the learning zones similar for each group. Again, the professor truly has the capability to structure the trip, course, or program so that it allows the greatest number of students to enter the learning zone.

Although it is ideal that some degree of learning can be achieved by the professor, we feel strongly, based upon our experiences that it's critical for the professor to stay within the comfort zone. However, they may have to periodically venture into learning zones to update course materials, explore other foreign countries, or gather other types of information. If the professor is not completely in the comfort zone, it may be appropriate to take a business executive on the international trip who has extensive knowledge in that country. Both the students and professors would then have a safety net and be more likely to occupy the appropriate zones for maximized student learning.

The professor must also be aware of students slipping into the panic zone, which results in adversity and psychological suffering (unless this is done deliberately to allow students to experience panic as a group. This can be beneficial to learning). The professor can determine certain safety nets in advance to push them back into their learning or even comfort zone. It is not detrimental for students to experience the panic zone as long as there is a way to quickly recapture them. Therefore, it is important to ensure that adequate safeguards are in place to pull the student back so the learning objectives are achieved.

The zone concept can be applied to any entrepreneurship course and is not necessarily restricted to a course that involves international travel. For instance, it can be used to structure business plan 
competitions domestically. It can also be used in situations where students present their business plans to local entrepreneurs. Since professors teaching the course have more detailed knowledge about the background, training and motivation levels of only the students, they can structure the course to provide optimal levels of eustrees. With a little thought and planning, professors teaching finance or marketing can easily implement the zone concept in their classes. For instance, a finance course that involves a group project with presentation can pair students in such a way that there is a student in the group with excel skills, another with presentation skills, etc. Clearly, the zone concept can be applied to any course, but the optimal mix of tasks would depend on the nature of the course.

All professors strive to maximize the learning experiences of their students. This study offers a framework for placing students in the learning zone, so that the objectives are met at the highest level possible. Advanced preparation is essential for the professor, beginning with a clear understanding of his or her own comfort zone. We hope that the framework provided is a valuable tool for professors to use in a variety of contexts to continually improve entrepreneurship education in light of an ever changing competitive landscape.

\section{REFERENCES}

Begley, T.M. and D.P. Boyd, 1987. Psychological characteristics associated with performance in entrepreneurial firms and smaller businesses. J. Bus. Venturing, 2: 79-93. DOI: 10.1016/0883-9026 (87)90020-6

Bennis, W.G. and R.J. Thomas, 2002. Crucibles of leadership. Harvard Bus. Rev., 80: 39-45.

Emmett, R.B., 1999. The economist and the entrepreneur: Modernist impulses in risk, uncertainty and profit. History Political Econ., 31: 29-52. DOI: 10.1215/00182702-31-1-29

Endo, J.J. and R.L. Harpel, 1982. The effect of studentfaculty interaction on students' educational outcomes. Res. Higher Educ., 16: 115-138. DOI: 10.1007/BF00973505

Envick, B.R. and P. Padmanabhan, 2006. A 21st century model of entrepreneurship education: Overcoming traditional barriers to learning. J. Ent. Educ.
Glennon, J.R., L.E. Albright and W.A. Owens, 1966. A Catalog of Life History Items. 1st Edn., Creativity Research Institute of the Richardson Foundation, Greensboro, NC., pp: 114.

Kahn, B.L., 2002. Co-opting the marketplace in the service of liberal arts education. Liberal Educ., 88: 54-58.

Kuh, G.D., 1994. Student Learning Outside the Classroom: Transcending Artificial Boundaries. 1st Edn., Graduate School of Education and Human Development, Washington, DC., ISBN-10: 1878380648, pp: 146.

Kuh, G.D., 1995. The other curriculum: Out-of-class experiences associated with student learning and personal development. J. Higher Educ., 66: 123155.

Lambing, P.A. and C.R. Kuehl, 2000. Entrepreneurship. 2nd Edn., Prentice Hall, Upper Saddle River, NJ., ISBN-10: 0130200433, pp: 301.

Nunn, L.E. and C.R. Ehlen, 2001. Developing curricula with a major emphasis in entrepreneurship - an accounting perspective. J. Applied Bus. Res., 17: 1-8.

Osborne, S.W., T.W. Falcone and P.B. Nagendra, 2000. From unemployed to entrepreneur: A case study in intervention. J. Dev. Entr., 5: 115-136.

Pascarella, E.T. and P.T. Terenzini, 1991. How College Affects Students: Findings and Insights from Twenty Years of Research. 1st Edn., Josey-Bass, San Francisco, ISBN-10: 1555423388, pp: 894.

Pascarella, E.T., 1980. Student-faculty informal contact and college outcomes. Rev. Educ. Res., 50: 545595. DOI: 10.3102/00346543050004545

Smith, B.N., J.S. Hornsby, M. Kite and B.N. Smith, 2000. Broadening the business curriculum via a cross-disciplinary approach: A mobile unit on cultural diversity. Education, 120: 713-721.

Wallace, W.L., 1967. Faculty and fraternities: Organizational influences on student achievement. Admin. Sci. Q., 1: 643-670. 